\title{
CONTACTLESS ICT TRANSACTION MODEL OF THE URBAN TRANSPORT SERVICE
}

\author{
Zoran PAVLOVIĆ ${ }^{\star}$, Milorad BANJANIN ${ }^{2}$, Jovanka VUKMIROVIĆ ${ }^{3}$, Dragan VUKMIROVIĆ ${ }^{4}$ \\ 1,3,4 Faculty of Organizational Sciences, University of Belgrade, Serbia \\ ${ }^{2}$ Faculty of Technical Sciences, University of Novi Sad, Serbia
}

Received 31 December 2018; revised 22 April 2019, 4 June 2019; accepted 4 July 2019;

first published online 4 May 2020

\begin{abstract}
The paper examines the problem of the productive functioning of an urban passenger transport system, which has a modular structure for the generation and exploitation of the urban transport services. The research objects consist of conventional, scalable and innovative contactless transaction models of an urban transport services in the case study of the Transport Organization (TO) - Joint Stock Company for Passenger Railway Transport "Serbia Trains" (Srbija Voz a.d.). The urban transport service is defined by invoking users, user expectations and requirements, the input data provided by users to a transport provider, the mechanisms for access and delivery of the service, the resources and roles responsible for delivery, security requirements and other parameters. The communication platform for modeling urban transport services in different transaction contexts is defined by the utilitarian framework with $6 \mathrm{~W}$ dimensions with situational mapping of the 6 Communication Dynamics Factors (6CDF). The technology-process restructuring was achieved with the scalable Information Technology (IT) model by implementing the elements of electronic business in the key activities of the supply of the train tickets. Using the results of the performed research, in the paper has been developed an innovative, non-contact ICT model of urban transport services on the platform for integrating the Internet service into the process-technology and behavioral-context structures.
\end{abstract}

Keywords: communication, customer, information system, interaction, transport organization, passenger transportation, public service, railway transport, e-ticket, e-process.

\section{Notations}

6CDF - 6 communication dynamics factors (space, relationships, time, interactions, roles, contexts); $6 \mathrm{~W}$ - who? what? where? when? how? why?;

BPEL - business process execution language;

F-F - face-to-face;

HTML - hypertext markup language;

HTTP - hypertext transfer protocol;

HTTPS - HTTP secure;

I/O - input/output;

ICOM - inputs, controls, outputs, and mechanisms;

ICT - information and communications technology;

IP - Internet protocol;

ISP - Internet service provider;

IT - information technology;

JMS - Java messaging systems;

MOM - message-oriented middleware;
PDF - portable document format;

SMPT - simple mail transfer protocol;

SMS - short message service;

SOA - service-oriented architecture;

SP - service provider;

TCP - transmission control protocol;

TO - transport organization;

URL - uniform resource locator;

XML - extensible markup language.

\section{Introduction}

In the research field of the improving transport systems, we recognized the need for design some holistic service integrated ICT transaction model of urban transport service in a developing environment. We discover that it takes into account readiness of the providers to adopt is,

*Corresponding author. E-mail: zoran.g.pavlovic@gmail.com 
as well as willingness of the users to accept it. In the considered setting, the proposed model is innovative and it can contribute to the development of the analyzed urban transport system. With that approach the motivation in this paper is to present the comparative advantages of a innovative contactless transactional ICT model of a multimodal transport service in which are integrated optimization factors from the interaction fields of people (user service and employees of SPs), processes (organizational, managerial and functional), technologies (technology of transport processes, IT, e-business and applications on the communication platforms) and environment (business environment and ambience of travel-transport of passengers).

A very up-to-date implementation of the new business paradigm, consisting of a man, the technology, the organization (process aspect) and the environment (Banjanin 2008a, 2008b; Van de Voorde, Meersman 2017), is explored for modeling the urban transport service whose process structures are analyzed in conventional and newer solutions of transport systems with a smaller or larger volume of transaction e-business activities (Milenković et al. 2018; Stoilova 2018). Urban transport systems are, as a rule, modular structures integrated by two or more specialized modules (Ghorabaee et al. 2017; Gil-Saura et al. 2017). The most common case is the integration (Wasiak et al. 2017) of the rail and road traffic modules into an intermodal TO with the functional role of SP.

According to the paradigm of the business unit, the urban transport service is structured with the processtechnology and behavioral-context components. The process-technology component is determined by the functional objects of a SP, the mechanisms for access and delivery of the services, the security requirements and the business-process-technological resources whose capacitive parameters are economical-technical - the transport speed, the ticket price, the efficiency, the reliability and the effectiveness of the transport systems. The behavioral-context component is determined by the professional roles of responsible operators to provide services with the management of the security factors and user factors - the input data they provide, needs-wishes, the requirements and expectations they have and the loyalty they show as well as the contextual information of significance for synchronizing the activities in the process structure of the service (Banjanin 2008a, 2008b).

In the process structures of newer models of the urban transport services, the advanced IT on the transaction communication platforms with segments of e-business are inevitably implemented (Šendelj, Ognjanović 2018; Banjanin 2008a, 2008b; Farkas et al. 2015). In the scalable ICT transaction model with electronic business, a platform of SOA is created, whose main roles are executed by software agents while in the behavioral component of the model, the main roles of human agents belong to the users of the transport service and to the employees of the TO.

On the basis of the theoretical analyzes and the results of field research of the characteristics of the reference- conventional transaction model and then the scalable IT model for the selected case study of the SP - Joint Stock Company for Passenger Railway Transport "Serbia Trains" (Srbija Voz a.d.; https://www.srbvoz.rs), we are created an innovative, contactless ICT transaction model of urban transport service.

\section{Materials and methods}

By survey of up-to-date research in the field of improvement of urban transport integration modeling can be apostrophize an example of the two-phase statistical model in the work (Jin et al. 2014) where the team of authors analyze the optimization of the localized metro network integrated with the bus services in multimodal urban transport. Things predominantly considered in that paper are safety aspects of the metro network integrated with the bus service for the selected application example.

However, in our case, it is used a multidisciplinary approach to development of a transactional ICT model of an integrated multimodal urban transport service with analysis of the interaction fields of the business entity paradigm factor. The initial research orientation is to integrate, in one transactional ICT model, the target needs, wishes and satisfaction of service users with the effects of operational certainty, functional similarity and reliability of the technologies and behavior of employees in the process structures of SPs, and the factors of the context of electronic business communication and the wider environment of multimodal urban transport service.

\subsection{Conventional transaction model of urban transport service}

The Srbija Voz a.d. operaters in the national and European transport market and in this paper it was selected for the case study of providers of urban transport services to users of mass transport of passengers. The transport module of the railroad is integrated with the road transport module. The users' wishes and expectations are oriented towards a comprehensive urban transport service. The processtechnology structure is characterized by the activities with the ICOM (Figure 1) I/O components (Banjanin, Gojković 2008; Kung, Zhong 2017).

By programming the ICOM components (Banjanin 2008a, 2008b), the SP sets a multi-dimensional strategic business goal and the essential dimensions are:

- to rationally exploit the transport resources and improve the development and implementation of the modern information and communication technologies in the structure of the urban transport service;

- to modernize the sales network with the emphasis on increasing the quality of the transport service and stimulating the loyalty of the users and acquiring new ones;

- to optimize the number of employees, their educational needs and continuous education for functional and the ICT competences. 


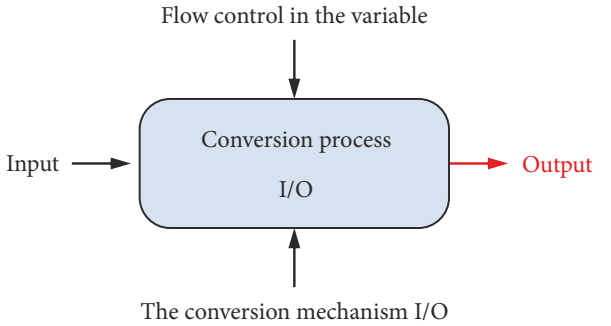

Figure 1. ICOM components of the structure of the activities of an urban transport services

This model is based on the platform of a transaction information and communication system with the business activities that are realized in the situational interweaving of the experienced interaction fields of service users and business-technical operators of SP (employees in TO). The interaction field determines the dominant interpersonal context of business communication with an instance F-F (Banjanin 2008a, 2008b; Wang et al. 2016), where successively and/or periodically shifts the operational activities of sending and receiving messages with a limited number of modalities of verbal and non-verbal codes for the transmission of the meaning.

The critical business activity is the purchase of train tickets at SP ticket cash desk, and the possible modalities of monetary transactions (payments) are in cash or with a bank payment card (Stjepanovic, Banjanin 2014). The interaction overlapping of the roles in messaging and transactions can be analyzed through the 6 semantic di- mensions of the context (6W) paired with 6 situational factors of the communication dynamics (6CDF) (Banjanin, Drakulić 2009; Ahmadinia et al. 2018). A tabular overview of the semantic dimensions of the context and factors of the communication dynamics for the users and SPs is given in Table 1 .

The conventional model of the urban transport service is characterized by various forms of data mapping (Banjanin 2011), i.e. one data (input or output) can be mapped as accurate or inaccurate, precise or imprecise, complete or incomplete, ie, can have multiple modalities of interpretation (total or unfinished, partial, complete or incomplete) with the inconsistent or redundant status of the generated information. Such oscillations in the mapping and interpretation of data are the result of the asymmetric impacts of certain situational factors of the communication dynamics that jeopardize functionality, effectiveness, efficiency and reliability of the service. One of the examples of such impacts is, as a rule, required service user waiting in the queue in limited manipulative space in passenger cash registers of the SP with an uncertain increase of the time for purchasing tickets. In these situational contexts, there is a high likelihood of generating a number of categories of interpersonal conflicts (Banjanin 2008a, 2008b) in instances of context (1:1) but also conflicts in instances of context $(1: N)$ and $(N: 1)$ The conflicts are manifested most often in the emotional dimension of the role performer in the interaction fields, among which is the possibility of a sudden lack of the necessary amount of cash available on the bank account of the user, or even

Table 1. Semantic dimensions of the context coupled with the situational factor of the dynamics of business communication

\begin{tabular}{|c|c|c|}
\hline $\begin{array}{l}\text { Semantic dimension } \\
\text { of context }(6 \mathrm{~W})\end{array}$ & Service user & SP \\
\hline $\begin{array}{l}\text { Who? } \\
\text { (roles) }\end{array}$ & $\begin{array}{l}\text { Users (real and potential) urban transport services } \\
\text { integrated from the rail and road transport } \\
\text { modules }\end{array}$ & $\begin{array}{l}\text { Operators-providers of urban transport services } \\
\text { from the modules of rail and road transport }\end{array}$ \\
\hline $\begin{array}{l}\text { What? } \\
\text { (relations/functions) }\end{array}$ & $\begin{array}{l}\text { Personal needs of the users for the urban } \\
\text { transport service realized by the activities } \\
\text { of procurement of tickets and transport }\end{array}$ & $\begin{array}{l}\text { Execution of reliable urban transport services to } \\
\text { users with satisfaction of quality standards in all } \\
\text { activities and fulfillment of the vision and aim of } \\
\text { effective and efficient operation of SPs }\end{array}$ \\
\hline $\begin{array}{l}\text { Where? } \\
\text { (space-location) }\end{array}$ & $\begin{array}{l}\text { Space-real physical locations for realizing the } \\
\text { needs of transport service users }\end{array}$ & $\begin{array}{l}\text { Operational area of the provider (physical and real) } \\
\text { for the provision of transport services }\end{array}$ \\
\hline $\begin{array}{l}\text { When? } \\
\text { (time-moment or } \\
\text { period) }\end{array}$ & $\begin{array}{l}\text { Open times of the traveler's cashbox - fixed daily } \\
\text { duration for the purchase of tickets and the period } \\
\text { of transport according to the selected parameters } \\
\text { from the transport timetable }\end{array}$ & $\begin{array}{l}\text { During the seven days of the week and according } \\
\text { to the winter/summer timetable }\end{array}$ \\
\hline $\begin{array}{l}\text { How? } \\
\text { (interaction/technology) }\end{array}$ & $\begin{array}{l}\text { By performing user roles in process-technology } \\
\text { transport activities and business transactions with } \\
\text { multimodal interactions in multi-dimensional } \\
\text { contexts of business systems }\end{array}$ & $\begin{array}{l}\text { Implementation of the programmed process } \\
\text { structure of urban transport service with operational } \\
\text { certainty, functional eligibility and reliability of the } \\
\text { transport system and technical infrastructure }\end{array}$ \\
\hline $\begin{array}{l}\text { Why? } \\
\text { (quality/pleasure) }\end{array}$ & $\begin{array}{l}\text { Satisfaction of personal wishes, needs, demands } \\
\text { and expectations of the user, in the shortest } \\
\text { possible period of time, to acquire-purchase } \\
\text { tickets and accomplish transport in accordance } \\
\text { with the guiding principles of quality service } \\
\text { and personal satisfaction }\end{array}$ & $\begin{array}{l}\text { Maintaining the reliable urban transport service } \\
\text { parameters and good image of the provider with } \\
\text { constant increase in quality and operating revenues } \\
\text { with reduced operating costs }\end{array}$ \\
\hline
\end{tabular}


"at home forgotten pay cards". This category of influence also includes technical problems in the interaction field of travel cash box of the service operator.

In the Section 2 of this paper, is presented the fieldnon-experimental research, performed in the case study of SP with a focus on individual dimensions of quality and overall customer satisfaction (Stjepanovic, Banjanin 2014). The research was carried out with the aim of modeling better process-technology and behavioral-context structures of an urban transport services.

\subsection{Scalable IT transaction model of the transport service in the Srbija Voz a.d.}

A scalable IT transaction model is a functional extension of the conventional one with currency transactions of ebusiness in the critical business activity of e-ticket purchasing. The operational technological-process structure of the urban transport service has been expanded and optimized using the ICT, primarily the "e-ticket" software application. In the interaction, fields have been changed the factors of communication dynamics with the effects of modified interaction in the manipulative space and the reduction in time consumption and the increase in user satisfaction in certain roles. Practically, the roles of the operator are significantly reduced, as well as relations and interactions in situational events and activities with users, because with the ICT the real physical space is being modified or "extended" with the virtual space for the critical activity of the service users, ie, purchase of the e-ticket for transport. With the proactive interaction (Banjanin 2008a, 2008b), with an application installed on a mobile device, the user can choose, validate and buy an e-ticket with electronic transactions with a commercial bank. The executed electronic transaction is verified by the provider operator with an e-mail to the user that contains the scanned eticket, but which he/she must print and own during the trip for possible "on-demand" operation. The transaction data and records generated by the e-business activities, during the transport and after finished the user needs, are stored in the TO database for checking (Bohm et al. 2005; Karthick, Velmurugan 2012).

The algorithmic steps that the user of the service must follow in the scalable IT transaction model are shown in Figure 2. Purchase of train tickets in internal traffic is enabled using the application on the website after confirming the request by pressing the "search" button (Figure 2), a list of trains for the given relation will be displayed and it is necessary to choose the appropriate one for the intended trip.

Upon the login, a new frame "purchase" (Figure 2) is opened where must be checked the requested data of the service users and, of course, confirm the purchase (Figure 2). Completed purchase involves the step in which, by confirming the button "buy tickets" (Figure 2), a new

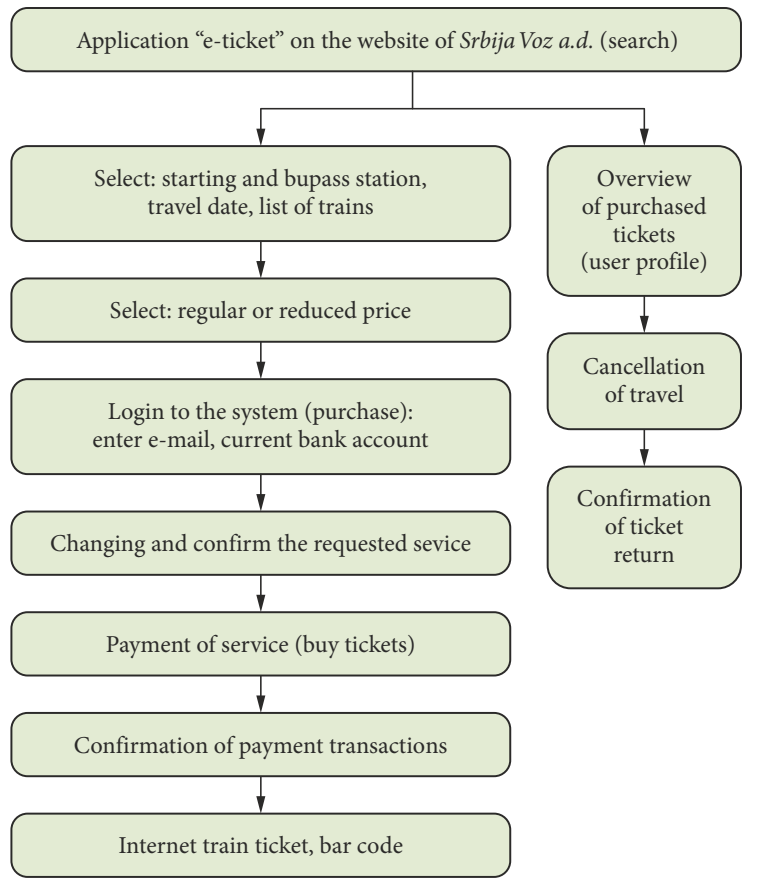

Figure 2. Review of necessary steps in the scalable IT transaction model of the Srbija Voz a.d. (https://www.srbvoz.rs)

frame is opened on the website of a commercial bank for finishing and payment. Based on the data entered on the cardholder, data processing is processed by confirming or rejecting the transaction. When the transaction is verified, the user of the service will receive the ticket in the PDFversion and a confirmation of the successful purchase of the ticket by e-mail. The service user must print this document and have it during the travel. In addition to this, the model has the "user profile" (Figure 2) option where, by choosing this service, a new web page is opened with an overview of all completed cash transactions for purchasing train tickets. On the same page, the user is given the opportunity to cancel the trip for personal reasons with a return notification by e-mail and the return card information, and the refunded money amount to be paid to the account from which the payment was made (Pavlović et al. 2016; Baranda et al. 2018).

The scalable IT transaction model of urban transport services expands the key business activity - procurement using the e-tickets in the rail transport module. It provides electronic exchange of information and messages, which follow the course of service activities and cash flows in the mutual communication between the service users and providers and in on-line banking using on-line services in electronic business through the computer networks. For this, a service orchestration is used as the concept of service coordination. The service orchestration defines the process flow and the pre-scheduled service priority with the activities of invoking one another. 


\subsection{Contactless ICT transaction model of urban transport services}

On the basis of an analytically-transparent research of contemporary literary sources and the characteristics of the traditional models of urban transport services as well as scalable transaction IT model with elements of electronic business in the case study of the SP - the Srbija $V o z$ a.d., an innovative, contactless ICT transport model of urban transport services was modelled.

The development of the model of a contactless IT transaction business of the urban transport service involves the integration of business e-processes into the TO in order to purchase one ticket in a digital copy that can be used in the rail and road transport of passengers. Therefore, the railway information infrastructure is not developed sufficiently to meet all the needs of the service users. One of the basic objectives is to identify and examine the necessary parameters for the application of the model, in order to improve the business operations in the TO (Xu et al. 2016). The railway passenger transport in its business already uses computers, the internet, and the integration of the business e-processes with other carriers is feasible (Pavlović, Vukmirović 2016). The primary goal of the research is the development of a new model of contactless IT transaction business in the TO, based on the Internet technologies. The Internet technologies are not only used to search for information and transactions in e-business, but also as a platform for providing services to users. For the integration of the web-service into the TO, the interaction process related to the service, its flow and the interdependent calls is defined. The business process implemented by the Internet technologies represents an eprocess. Automation of the e-processes in the TO reduces costs (employee salaries, ticket printing, distribution, storage, etc.), improves the quality, procurement, and speed of the service takeover.

The contactless ICT transaction business model includes services and messages in SOA. This architecture supports the transformation of business environments where the services are loosely interconnected, which communicate among themselves with message exchange within given activities with the basic goal of completing business processes. The services represent functional business components that give the desired results with the appropriate design where easy accessibility is provided to service users. The SOA enables work of applications that contain ready-made software services whose functionalities are independent of each other. In order to achieve the communication, defined protocols are used that describe how two or more services are addressed to one another. This architecture enables the connection and matching of the services in the business process.

\section{Results and discussion}

The above-mentioned shortcomings of the conventional transaction model were investigated by a surveying method by interviewing the current and potential pas- sengers - users of services and the operators-employees in the Srbija Voz a.d. For the purposes of the survey, the user service profile and the operator profile in the passenger cash box offices of the SP were made with the aim of obtaining the necessary parameters as input data for improving the effectiveness and efficiency. The parameters of the characteristic user profile are personal characteristics: extrovertedness, willingness to cooperate and openness. The typical profile of an SP operator is determined by the following parameters: age, functional level of education, work experience, foreign language skills, advanced digital competence, health status, proactivity and work flexibility, teamwork skills and the will to sacrifice for the interests of the organization.

The sample of the SP consists of 105 employees who are in direct business communication with the users, and they responded to 15 questions with five given responses in the survey questionnaire. Input data in certain subjects include: years of service, level of education, level of IT education, IT certificates, participation in IT projects, competence analysis from IT, readiness for new ways of doing business, etc. The Likert-scale was used for evaluation of each answer represented by a number $(1-$ no, $2-$ not sure, 3 - maybe, 4 - very likely and 5 - yes). Based on the data collected by the survey and processed by statistical analysis using the IBM SPSS ${ }^{\circ}$ software (https://www. ibm.com/analytics/spss-statistics-software), the information about the profile of the surveyed operators was obtained through the frequency distribution of the response value. Based on the obtained data about the profile in the study, the attitude of the employees towards the development and implementation of the new model of the IT transaction business is partially positive.

The sample of service users is made up of 78 surveyed students and citizens-passengers on the Belgrade - Novi Sad - Belgrade railroad, traveling daily with railways, using mobile devices and the Internet. The main research variables are: satisfaction with the current service, quality of service, objections to the service provided, objections to the work of employees in the TO, readiness for the implementation of new business methods, trust in the TO, etc. Comparative view of transaction models was generated based on the situation parameters that include: space, time, roles, relations, interactions and environment (Table 2).

Every technology innovation, based on the Internet technology leads to decrease in the number of employees. The Srbija Voz a.d. has 270 employees who perform the activities of issuing the tickets and 392 employees for control where the average gross salary is about 430 EUR, and in the budget must be allocated about 284660 EUR/ month. At the annual level, the amount is much higher and amounts to about 3415920 EUR. An annual savings are around 1100000 EUR and it can be reoriented for the development and application of new technologies. Reducing the costs of employees' salaries and implementing new technologies directly affects the overall operation of the TO (Chabot et al. 2018). 
Table 2. Comparative view of the factors of the communication dynamics of the conventional, scalable IT and innovative contactless ICT transaction model of urban transport service (adapted according to Banjanin (2008a, 2008b))

\begin{tabular}{|c|c|c|c|}
\hline $\begin{array}{ll}\text { Situation } \\
\text { parameter }(6 \mathrm{CDF})\end{array}$ & $\begin{array}{l}\text { Conventional transaction } \\
\text { model }\end{array}$ & $\begin{array}{l}\text { Scalable IT transaction } \\
\text { model }\end{array}$ & $\begin{array}{c}\text { Contactless ICT transaction model } \\
\text { of urban transport service }\end{array}$ \\
\hline Space & $\begin{array}{l}\text { Traveler ticket cash desk } \\
\text { in business facilities of } \\
\text { the TO authorized for } \\
\text { selling tickets and direct } \\
\text { communication between } \\
\text { parties }\end{array}$ & $\begin{array}{l}\text { Virtual cash desk for selecting and } \\
\text { paying for services and the user going } \\
\text { to physical facilities of the TO to take } \\
\text { over the ticket }\end{array}$ & $\begin{array}{l}\text { Virtual cash desk of the TO based } \\
\text { on contactless business (selection } \\
\text { and payment of services, obtaining } \\
\text { a digital record that represents an } \\
\text { e-ticket to the user's device) }\end{array}$ \\
\hline Time & $\begin{array}{l}\text { Limited daily working } \\
\text { hours of traveler cash } \\
\text { desk in the TO }\end{array}$ & $\begin{array}{l}24 / 7 \text { and the time necessary to take } \\
\text { over the ticket }\end{array}$ & $\begin{array}{l}24 / 7 \text { for the selection and payment } \\
\text { of the service with obtaining a } \\
\text { digital ticket to an SMS of the users }\end{array}$ \\
\hline Roles & $\begin{array}{l}\text { Service user with need, } \\
\text { request and expected } \\
\text { provided service for } \\
\text { ticket / SP implementer of } \\
\text { direct distribution }\end{array}$ & $\begin{array}{l}\text { Selection and payment for the service } \\
\text { through the TO service and going to } \\
\text { the carrier's cash desk for to take } \\
\text { over / provide the resources in the } \\
\text { TO for the realization of the request }\end{array}$ & $\begin{array}{l}\text { Ordering, selling and delivering } \\
\text { the required service through the } \\
\text { TO service in contactless business } \\
\text { with the service user }\end{array}$ \\
\hline Relationships & $\begin{array}{l}\text { The user of the service } \\
\text { in F-F communication } \\
\text { with the cashier in all } \\
\text { transactional activities }\end{array}$ & $\begin{array}{l}\text { Verbal communication between the } \\
\text { user and the TO using the Internet } \\
\text { network in the exchange of messages } \\
\text { and going to the cash desk to take } \\
\text { over }\end{array}$ & $\begin{array}{l}\text { Contactless communication } \\
\text { between the service user and the } \\
\text { TO in the transactional activities } \\
\text { of ordering, paying and obtaining } \\
\text { a transport ticket in a digital form } \\
\text { with a service requester }\end{array}$ \\
\hline Interactions & $\begin{array}{l}\text { Service user with the } \\
\text { employees in the TO }\end{array}$ & $\begin{array}{l}\text { The user with the server in the } \\
\text { TO to select, order and pay for the } \\
\text { requested service, and the F-F with a } \\
\text { cashier to take over the ticket }\end{array}$ & $\begin{array}{l}\text { The contactless interaction } \\
\text { between the service users and } \\
\text { employees in the TO for ordering, } \\
\text { buying/selling and owning a ticket } \\
\text { works for "show on-demand" }\end{array}$ \\
\hline Contexts & $\begin{array}{l}\text { Physical access of the } \\
\text { user to the traveler cash } \\
\text { desk / workspace of a TO } \\
\text { employee }\end{array}$ & $\begin{array}{l}\text { Network and service operations } \\
\text { between the service user and } \\
\text { employees in the TO / going to the } \\
\text { carrier's cash desk to take over the } \\
\text { ticket }\end{array}$ & $\begin{array}{l}\text { Development of new transactional } \\
\text { business platforms between the } \\
\text { service user and the TO to select, } \\
\text { pay and get the ticket in a digital } \\
\text { form }\end{array}$ \\
\hline
\end{tabular}

From the economic point of view, the TO allocates certain amount of money to print tickets. Special paper, protective holograms, hardware and software equipment are required to print the tickets. The Srbija Voz a.d. for printing the transport tickets has allocated about 204079 EUR for the last three years.

\section{Modelling of the innovative contactless ICT transaction model of urban transport services}

Technological innovations in the process structures of an urban transport service involve not only extending but in general, the substitution of traditional contacts in the real physical space of the SPs with the contactless transaction communication models of the providers and the users. The target orientation in designing and implementing the model is not only to increase the operational certainty, functional eligibility and reliability of a TO's resources, including the technical infrastructure, the business efficiency, but above all to increase the level of quality that is an indicator of "user satisfaction measurement" (Abenoza et al. 2017). The achievement of these goals implies an intensive and scalable information architecture whose com- ponents are hardware, software, network with communication elements, databases and information engineering.

The model is oriented to several subjects applied with specific goals. The challenge is the integration of the business process of the railway TO with other TOs, where road transport vehicles are also included. Thus, the integration with other modes of transport allows the service user one ticket for the predetermined route from the point $\mathrm{A}$ to the point $\mathrm{B}$, using multiple modules of transport. The capabilities of the TO e-business include integrating, collaborating and proactive Internet communication with the implementation of new services in order to meet the demands and needs of the service users (Wheat, Wardman 2017; Ai et al. 2015).

The service integration in the new business model of integrated TOs enables the activities of purchasing a single transport ticket that can be used in all means of transport. The service integration also provides more cheaper transportation tickets (Sankaranarayanan et al. 2017). The development of new models also implies the technicaltechnological transformation of the organization (Zeng et al. 2008). 
The user of the service, on the basis of the data that he/ she can see through the internet technologies on his/her device, has the possibility of choosing and deciding. The interaction generated by the user of the service is provided by connecting to the Internet through ISPs communications links. The Internet platform is a system of logically interconnected address space based on the IP that allows communications using the TCP/IP. The TCP allows the data exchange between applications when buying a ticket. The HTTPS provides a secure server identification. The user via the Internet and the mobile phone or computer sends a HTTP request with a communication protocol containing the URL address to the web-server, where the application server is activated. The application server sends a HTML page to the web-server that is forwarded to the user of the service (Kurose, Ross 2014). The HTML standard allows the user to switch from one website to another, to search and select the service in the e-process of buying a ticket. The e-card model in the rail transport is linked to an already existing model called "Orka", which allows the issuance and reservation of tickets in internal passenger traffic. The "Orka" system includes the infrastructure elements of the railway in the territory of the Serbia, ticket cash desks at stations and agencies that have signed a contract on business cooperation.

With this model, the payment with a payment card means transferring the service users from the website of Srbija Voz a.d. to the website of the Intesa bank (https:// $w w w$. bancaintesa.rs). Rerouting implies that the user of the service enters the e-process of payment when he/she clicks on the "buy tickets" button; he/she is transferred to the website of the payment processor of the Intesa bank. The model uses e-mail for external communication about purchased tickets and a confirmation when the service user has given up the travel.

The input parameters of the service in a contactless ICT transaction model are required by the user of the service while the output parameters depend on the interaction achieved in the communication with the TO (integrated rail and road passenger transport) as a SP (Gregorio et al. 2005). Interaction in a contactless ICT transaction model includes a set of messages that are exchanged between the service users and SPs, within the e-process of transactions to achieve the intended goal. Using the SOA technology, the messages are presented in the XML format and communicate with each other through the SMPT, HTTP or JMS (Ghorabaee et al. 2017; Choi et al. 2009).

Each message has a service user who initiates the sending of a request, a SP who receives, and a specific action, which is expressed for the purpose of sending. To start the activity, a message is used that represents the communication specification that transmits the necessary information between the objects to start the activity. The service of a contactless ICT transaction model is defined by a core that represents the ability of the service to implement the e-process of message exchange and the interaction field that is reflected through the ability of the users and the IT administrators to realize the communication (Figure 3).

In the innovative contactless ICT transaction model of an urban transport service the interaction field has the role of the cooperation activities, which are connected to the messages in the process of communication and can be presented in the following way:

$$
A \approx C \cdot R \cdot P^{*} \text {. }
$$

The subset $A$ represents the cooperation transaction patterns as the ability of the interaction field, the subset $C$ represents the participants in the interaction (service resources) and $s=\left\langle c_{s}, r_{s}, P_{s}\right\rangle$ represents a component that explicitly borders with the role $R$ and uses a set of interaction e-processes $P^{*}$. The ultimate goal of the development of the ICT transaction model is a service determined by the service user factors, his/her needs, requirements and

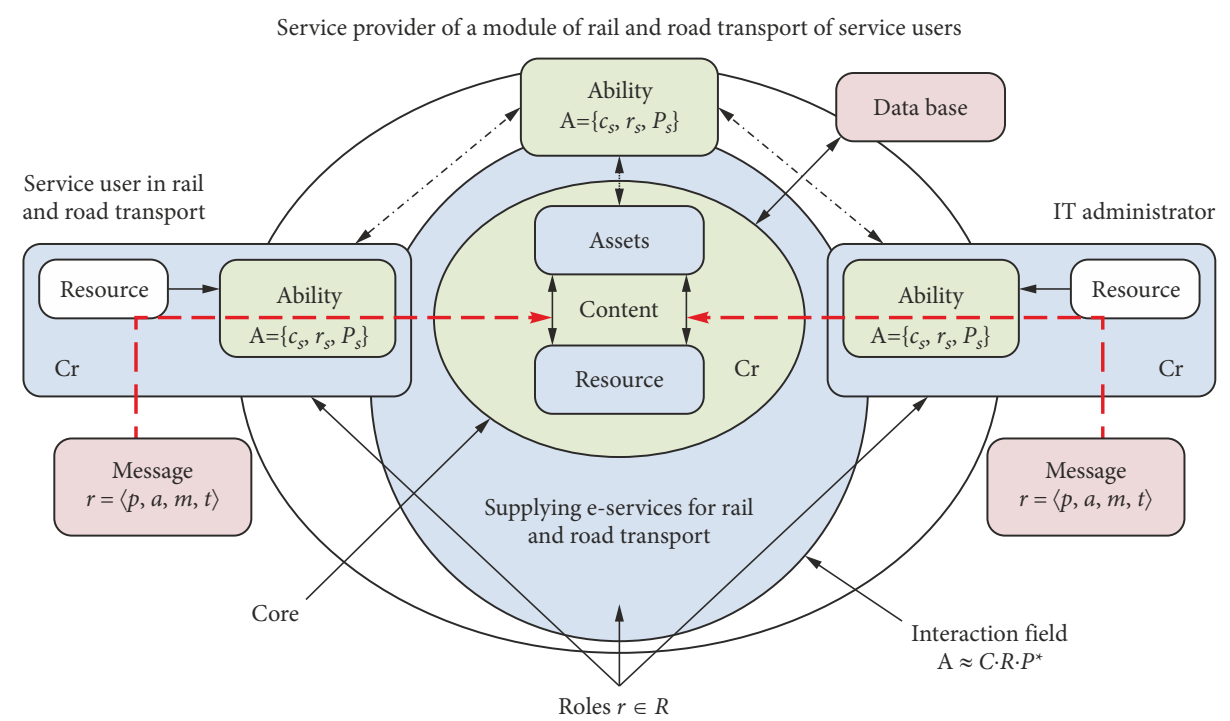

Figure 3. Situational complexity of the factors of the communication dynamics and configuration of the ability status in the ICT transaction model of an urban transport services (adapted according to Banjanin, Gojković (2008); Banjanin (2008a, 2008b); Stjepanovic, Banjanin (2014); Banjanin, Drakulić (2009)) 
expectations, the resources and mechanisms for access and delivery, which are analyzed from the database. The ICT transaction model favors a service information request $r$, which includes what is required $p$, to whom it is required $a$, how to respond to the request $m$ and when it is appropriate $t$, which can be presented as follows:

$$
r=\langle p, a, m, t\rangle \text {. }
$$

If $r$ represents a request for service information, $p$ represents and determines the type of information and at the same time the limit of the value of the size of the expected results, $a$ determines the service user, $m$ represents a protocol that ensures that the information is shared in the right way and $t$ represents the time periods that can be: a moment before a certain time, as soon as possible, at a specific time or moment in time that is periodically repeated.

Modelling of the architecture (Figure 4) of a contactless ICT transaction model is based on the analysis of the dynamic complexity (configuration of the state) of interactions of the four components of the whole that represent the modern business process paradigm (technology, organizational processes, environment and human resources).

The technology in the architecture of the model represents the software and hardware components of TOs for rail and road passenger transport, services for communication and messaging services, as well as SPs based on the ICOM components of functional and business activities.

For the realization of the business process, the "message" and its flow is emphasized through a service that is covered by the SOA technology using a MOM server (Šumak et al. 2017). The BPEL is used to describe business processes to the workflow. The JMS protocol is used to transport messages (Ansari et al. 2017).

The environment of the innovative contactless ICT transaction model architecture provides communication between the service user and the SP in order to obtain the necessary information about the location, user, time, activity, history or computer entity or information that can be used to characterize the situation (status) of an entity (a person, place, or object, which are considered relevant for the interaction of the users and the application, including the user itself and the application) (Banjanin 2008, 2008b). The overview and the meaning of the symbols that are applied in the algorithm are shown in the Table 3.

In the innovative contactless ICT transaction model there is presented an algorithm (Figure 5) for the activities related to the message exchange in the e-process of communication between the service user and the provider, and it can be presented in the following way:

$$
e t=\langle A r, \text { Aro, B1,B2, B3, B4, B5 }\rangle \text {. }
$$

The electronic ticket $e t$ in the e-process is generated by the transaction activities of the application $A P$, where is enabled the selection in the rail TO $A r$, in the road TO Aro and contactless payment for the service through a bank $A B$. The subset $A r$ comprises the following steps: the selection of the distance $r 1$, date $r 2$, number of passengers $r 3$ and the type of place $r 4$. While in the road TO Aro the service user selects the distance ro1, date of travel ro2 and number of passengers ro3. The service user pays for the service contactless through a bank $A B$ with the following steps: logging of the user $B 1$, entering the account $B 2$, payment $B 3$, confirmation of payment for the service $B 4$ and rejection of the requested service $B 5 . V 1$ is validation of an e-ticket in the mode of transport and $V 2$ is validation during the control process.

In a contactless ICT transaction model, the user of the service uses an application in a mobile device from any place and at any time with the Internet to communicate with the SP to order and purchase a single ticket valid for the rail and road transport modes.

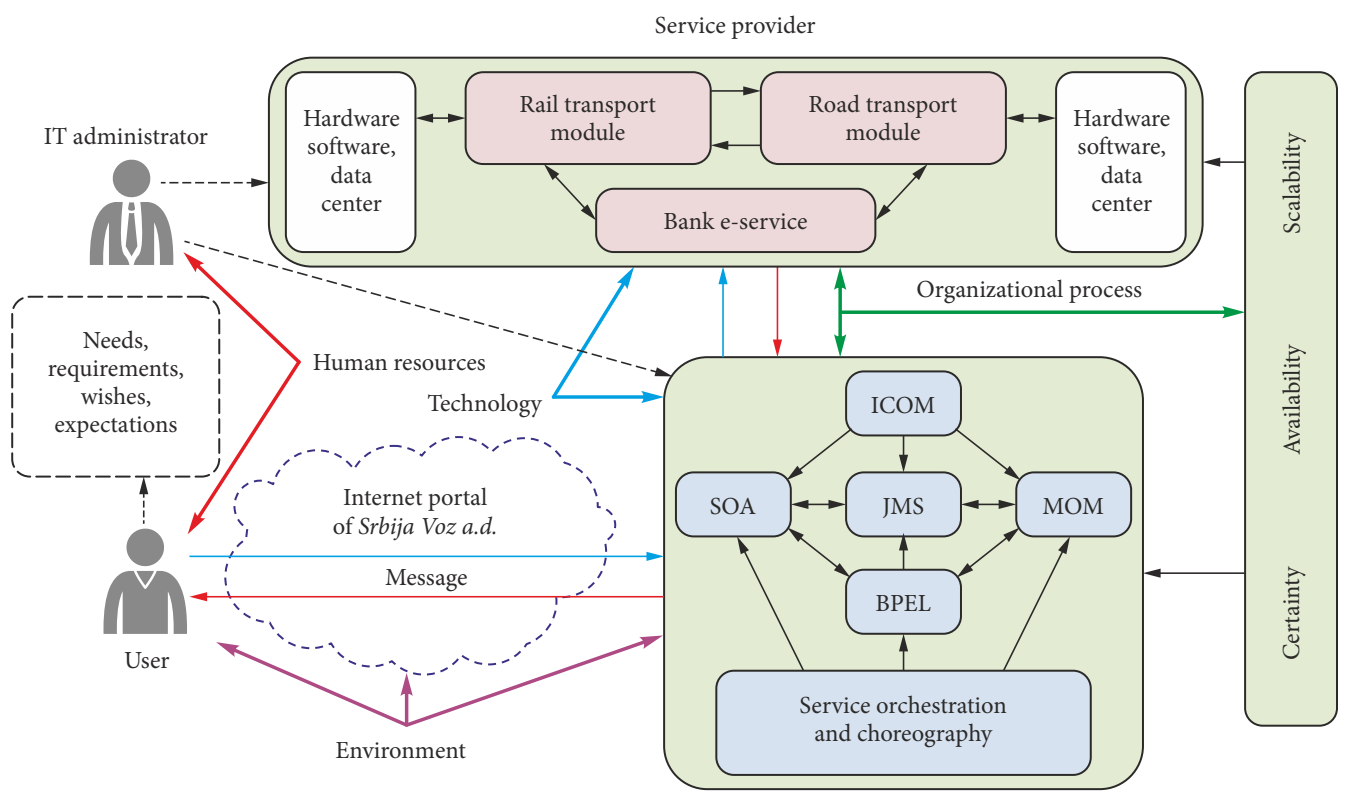

Figure 4. Modelling of the architecture of a contactless ICT transaction model 
Table 3. The overview and the meaning of the symbols that are applied in the algorithm

\begin{tabular}{|c|l|}
\hline Symbol & \multicolumn{1}{|c|}{ Meaning of symbols } \\
\hline et & electronic ticket \\
\hline$A P$ & software application \\
\hline$A r$ & selection in railway TO \\
\hline$r 1$ & selection of a relation in the railway TO \\
\hline$r 2$ & selection of travel date in railway TO \\
\hline$r 3$ & $\begin{array}{l}\text { selection of the number of passengers } \\
\text { in the railway TO }\end{array}$ \\
\hline$r 4$ & selecting the type of place in the railway TO \\
\hline$A r o$ & road TO \\
\hline$r o 1$ & selection of a relation in the road TO \\
\hline$r o 2$ & selection of travel date in road TO \\
\hline$r o 3$ & $\begin{array}{l}\text { selection of the number of passengers } \\
\text { in the road TO }\end{array}$ \\
\hline$A B$ & application bank \\
\hline$B 1$ & user logging \\
\hline$B 2$ & input user account \\
\hline$B 3$ & payment of the requested service \\
\hline$B 4$ & confirmation of paid service \\
\hline$B 5$ & refusal of the requested service \\
\hline$V 1$ & validation of an e-ticket in the mode of transport \\
\hline$V 2$ & validation during the control process \\
\hline
\end{tabular}

The user of the service in the rail transport module selects and requests the destination and date of the travel, the number of passengers and the type of place (seat or bed). If the requested service is available on the basis of the available resources of the TO, the service user may continue to select the parameters for the road module. In the event that the TO does not have the parameters required by the user, the user is automatically returned to the beginning of the application to re-select the next train based on the timetable, if there are no free seats or the like in the requested one.

The next option is to skip the road module in order to start the process of payment for a service that entails logging, entering the user's bank account and paying for the requested parameters. When the bank confirms the payment transaction, the user receives the e-card with the service specification on the mobile device he/she uses for the validation on the device installed in the vehicle. At the request of the authorized employees in the TO for the control, the user also shows the et on his/her mobile device.

When the user of the service selects the requested service in the rail module, he/she switches to the selection of the parameters in the road module, which includes the destination and date of the travel with the number of passengers. If the requested service is available based on the available resources, the service user enters the payment process. If one or more parameters are not available, the user has the ability to return and re-select the service, for example, when he/she ends the travel with the rail trans-

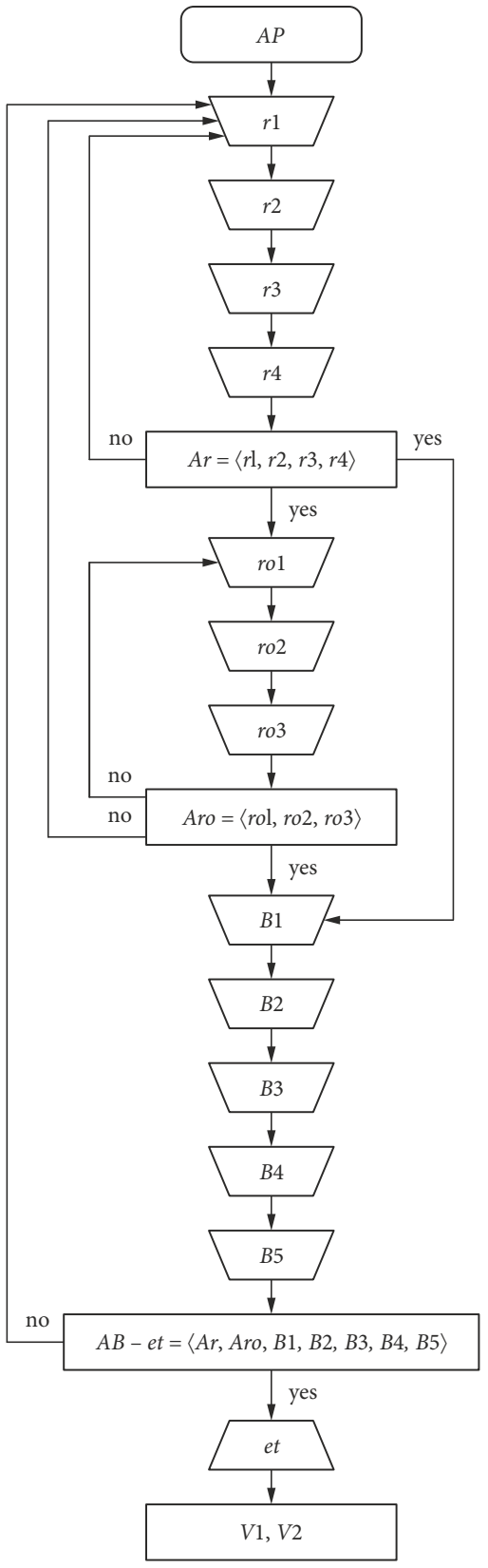

Figure 5. Flow algorithm of activities in a contactless ICT transaction model of urban transport services

port and in the first road vehicle there is no place he/she can choose the next one that suits.

In the last step regarding the payment, there is a possibility that the service user does not have enough money and is automatically returned to the beginning of the application. In this case, the required parameters are released and are available to potential users.

\section{Conclusions}

Innovative contactless ICT transaction model of urban transport service is conceived as a unique whole of technological, behavioral, process and contextual components of the functioning and operation of an SP and the com- 
plexity of the interactions with the service users. The initial hypothetical setting of the research is oriented towards modelling the architecture with the goal of improving the performance of functional and transactional business processes and raising the customer satisfaction to a competitive level of service quality. The results of the field survey of the service user profiles views of the representative sample confirm the hypothetical attitude of the readiness to accept the contactless ICT transaction model of an urban transport service in the e-business of the SP. The user readiness indicator for acceptance of the innovative technologies is at a higher level than the indicator of the willingness of employees in the TO, which express certain indecision and mistrust towards new business models.

A characteristic service user profile in the survey sample is determined by the extrovertibility, the willingness to cooperate and the openness of students and citizens who in the process activities of the transport service proactively operate with a frequent use of mobile devices on a platform of the Internet communication. In the selected sample of SPs, the Srbija Voz a.d., a typical profile of the employed operators has an indicator of an average age of about 46 years. The significant connection between the levels of functional education and readiness to accept innovative technologies in the urban transport service is shown with an indicator of willingness to accept of $49 \%$ within the employees with secondary education, and of only $15.7 \%$ within higher education employees. The shown indicators point to the need for more quality organizational learning and continuous business education of the employees, especially in the field of information and communication technologies and the improvement of professional and digital competences.

The contactless ICT transaction model of urban transport service more consistently incorporates the wishes, requirements and needs of the service users in interactive messaging and business transactions with the TO. The ebusiness infrastructure of the SP includes hardware and software components of the system, human resources, Internet technologies, mobile technologies, security devices and digital protection of the service users. The availability of the web-services in the Internet communication of the users from any mobile device positioned at any physical location and at any time, allows interactions with the applications of the models tested in real conditions of the implemented test scenarios. In the final result it affects the improvement of the image of the TO in the business environment and the creation of a positive ambient climate for increasing the total quality of the service and maintaining the level of shown trust of the service users.

\section{Disclosure statement}

We work authors declare that we do not have competing finance, professional and personal interests from other parties.

\section{References}

Abenoza, R. F.; Cats, O.; Susilo, Y. O. 2017. Travel satisfaction with public transport: determinants, user classes, regional disparities and their evolution, Transportation Research Part A: Policy and Practice 95: 64-84.

https://doi.org/10.1016/j.tra.2016.11.011

Ahmadinia, M.; Movaghar, A.; Rahmani, A. M. 2018. Semantic data gathering of physical entities in semantic sensor networks using software agents, Information Technology and Control 47(2): 167-183. https://doi.org/10.5755/j01.itc.47.2.16073

Ai, B.; Guan, K.; Rupp, M.; Kurner, T.; Cheng, X.; Yin, X.-F.; Wang, Q.; Ma, G.-Y.; Li, Y.; Xiong, L.; Ding, J.-W. 2015. Future railway services-oriented mobile communications network, IEEE Communications Magazine 53(10): 78-85. https://doi.org/10.1109/MCOM.2015.7295467

Ansari, S.; Yoon, S.; Albert, L. A. 2017. An approximate hypercube model for public service systems with co-located servers and multiple response, Transportation Research Part E: Logistics and Transportation Review 103: 143-157 https://doi.org/10.1016/j.tre.2017.04.013

Banjanin, M. 2011. Kompleksnost podataka i različiti prostori u ontološkim modelima, u Spomenica akademika Veselina Perića. Odjeljenje prirodnomatematičkih i tehničkih nauka, Akademija nauka i umjetnosti Republike Srpske, 15: 447-464. (in Serbian).

Banjanin, M. 2008a. Komunikacija sa klijentima. Beograd, Srbija. 242 s. (in Serbian).

Banjanin, M. 2008b. Naučnoistraživačka metodologija. Beograd, Srbija. 456 s. (in Serbian).

Banjanin, M.; Drakulić, G. 2009. Simetrične kombinacije multimodalnih interakcija u inteligentnoj okolini, u Tehnologija, informatika, obrazovanje za društvo učenja i znanja: 5. međunarodni simpozijum, 19-20. juna 2009. godine, Čačak, Srbija, 2: 125-136. (in Serbian).

Banjanin, M.; Gojković, P. 2008. Analitičke procedure u inženjerskim disciplinama. Doboj, Srbija. 420 s.(in Serbian).

Baranda, J.; Mangues-Bafalluy, J.; Pascual, I.; Nunez-Martine, J.; De La Cruz, J. L.; Casellas, R.; Vilalta, R.; Salvat, J. X.; Turyagyenda, C. 2018. Orchestration of end-to-end network services in the 5G-crosshaul multi-domain multi-technology transport network, IEEE Communications Magazine 56(7): 184-191. https://doi.org/10.1109/MCOM.2018.1701329

Bohm, A.; Murtz, B.; Sommer, G.; Wermuth, M. 2005. Locationbased ticketing in public transport, in Proceedings. 2005 IEEE Intelligent Transportation System, 16 September 2005, Vienna, Austria, 837-840. https://doi.org/10.1109/ITSC.2005.1520158

Chabot, T.; Bouchard, F.; Legault-Michaud, A.; Renaud, J.; Coelho, L. C. 2018. Service level, cost and environmental optimization of collaborative transportation, Transportation Research Part E: Logistics and Transportation Review 110: 1-14. https://doi.org/10.1016/j.tre.2017.11.008

Choi, B.; Raghu, T. S.; Vinze, A.; Dooley, K. J. 2009. Process model for e-business standards development: a case of ebXML standards, IEEE Transactions on Engineering Management 56(3): 448-467. https://doi.org/10.1109/TEM.2009.2013828

Farkas, K.; Feher, G.; Benczur, A.; Sidlo, C. 2015. Crowdsending based public transport information service in smart cities, IEEE Communications Magazine 53(8): 158-165. https://doi.org/10.1109/MCOM.2015.7180523

Ghorabaee, M. K.; Amiri, M.; Zavadskas, E. K.; Antuchevičienè, J. 2017. Assessment of third-party logistics providers using a CRITIC-WASPAS approach with interval type-2 fuzzy set, 
Transport 32(1): 66-78.

https://doi.org/10.3846/16484142.2017.1282381

Gil-Saura, I.; Ospina-Pinzón, S.; Ruiz-Molina, M.; BerenguerContri, G. 2017. Methodologies for evaluating service quality: evidence from freight services, International Journal of Transport Economics - Rivista internazionale di economia dei trasporti 44(1): 99-118. https://doi.org/10.19272/201706701005

Gregorio, D. D.; Kassicieh, S. K.; De Gouvea Neto, R. 2005. Drivers of e-business activity in developed and emerging markets, IEEE Transactions on Engineering Management 52(2): 155-166. https://doi.org/10.1109/TEM.2005.844464

Jin, J. G.; Tang, L. C.; Sun, L.; Lee, D. H. 2014. Enhancing metro network resilience via localized integration with bus services, Transportation Research Part E: Logistics and Transportation Review 63: 17-30. https://doi.org/10.1016/j.tre.2014.01.002

Karthick, S.; Velmurugan, A. 2012. Android suburban railway ticketing with GPS as ticket checker, in 2012 IEEE International Conference on Advanced Communication Control and Computing Technologies (ICACCCT), 23-25 August 2012, Ramanathapuram, India, 63-66.

https://doi.org/10.1109/ICACCCT.2012.6320742

Kung, L.-C.; Zhong, G.-Y. 2017. The optimal pricing strategy for two-sided platform delivery in the sharing economy, Transportation Research Part E: Logistics and Transportation Review 101: 1-12. https://doi.org/10.1016/j.tre.2017.02.003

Kurose, J. F.; Ross, K. W. 2014. Umrežavanje računara: od vrha ka dnu. Beograd: CET. 892 s. (in Serbian).

Milenković, M.; Švadlenka, L.; Melichar, V.; Bojović, N.; Avramović, Z. 2018. SARIMA modelling approach for railway passenger flow forecasting, Transport 33(5): 1113-1120. https://doi.org/10.3846/16484142.2016.1139623

Pavlović, Z.; Vukmirović, A. 2016. Posebna ponuda železnice za izdavanje voznih isprava rezervisanih i kupljenih putem interneta, u YUINFO 2016: Zbornik radova, 28. Februar - 02. Mart 2016. godine, Kopaonik, Srbija, 226-231. (in Serbian).

Pavlović, Z.; Vuksanović, J.; Gavrić, Ž. 2016. Definisanje multimedijalne strategije za povećanje broja korisnika usluga železnice, FBIM Transactions 4(2): 111-119.

https://doi.org/10.12709/fbim.04.04.02.11 (in Serbian).

Sankaranarayanan, H. B.; Rukmangadha, P. V.; Grosche, T. 2017. A combinatorial approach for calculating rail-fly connectivity index in India based on fuzzy logic, in 2016 Future Technologies Conference (FTC), 6-7 December 2017, San Francisco, CA, US, 150-155. https://doi.org/10.1109/FTC.2016.7821604

Stjepanovic, A.; Banjanin, M. 2014. Distributed multimedia information system for traffic monitoring and managing, Lecture Notes in Computer Science 8669: 475-483. https://doi.org/10.1007/978-3-319-10840-7_57

Stoilova, S. 2018. Study of railway passenger transport in the European Union, Tehnički vjesnik 25(2): 587-595. https://doi.org/10.17559/TV-20160926152630

Šendelj, R.; Ognjanović, I. 2018. Multi-criteria decision making for optimal configuration of business process model families, Information Technology and Control 47(3): 532-563. https://doi.org/10.5755/j01.itc.47.3.18652

Šumak, B.; Heričko, M; Budimac, Z.; Pušnik, M. 2017. Investigation of moderator factors in e-business adoption: A quantitative meta-analysis of moderating effects on the drivers of intention and behavior, Computer Science and Information Systems 14(1): 75-102. https://doi.org/10.2298/CSIS160902033S

Van de Voorde, E.; Meersman, H. 2017. Transport research for a changing and sustainable future, International Journal of Transport Economics - Rivista internazionale di economia dei trasporti 44(1): 11-23. https://doi.org/10.19272/201706701001
Wang, W.; Lin, Y.; Zhao, Y.; Zhang, G.; Zhang, J.; Han, J.; Chen, H.; Hou, B.; Ji, Y.; Zong, L. 2016. First demonstration of virtual transport network services with multi-layer protection schemes over flexi-grid optical networks, IEEE Communications Letters 20(2): 260-263. https://doi.org/10.1109/LCOMM.2015.2509066

Wasiak, M.; Jacyna, M.; Lewczuk, K.; Szczepański, E. 2017. The method for evaluation of efficiency of the concept of centrally managed distribution in cities, Transport 32(4): 348-357. https://doi.org/10.3846/16484142.2017.1345005

Wheat, P.; Wardman, M. 2017. Effects of timetable related service quality on rail demand, Transportation Research Part A: Policy and Practice 95: 96-108. https://doi.org/10.1016/j.tra.2016.11.009

Xu, C.; Zhao, J.; Muntean, G.-M. 2016. Congestion control design for multipath transport protocols: a survey, IEEE Communications Surveys \& Tutorials 18(4): 2948-2969. https://doi.org/10.1109/COMST.2016.2558818

Zeng, Q.; Chen, W.; Huang, L. 2008. E-business transformation: an analysis framework based on critical organizational dimensions, Tsinghua Science \& Technology 13(3): 408-413. https://doi.org/10.1016/S1007-0214(08)70065-8 